\title{
Variations of workload and well-being measures across a professional basketball season
}

\section{Variações das medidas de carga e bem-estar durante um período profissional de basquetebol}

\author{
Mónica Ferreira ${ }^{1}$ \\ (D) https://orcid.org/0000-0003-2901-5639 \\ Miguel Camões ${ }^{1,2}$ \\ (D) https://orcid.org/0000-0002-7786-8970 \\ Ricardo Franco Lima ${ }^{1,2}$ \\ (D) https://orcid.org/0000-0003-3552-7534 \\ Rui Silva ${ }^{1}$ \\ (D) https://orcid.org/0000-0003-3380-864X \\ Henrique de Oliveira Castro ${ }^{3}$ \\ (D) https://orcid.org/0000-0002-0545-164X \\ Bruno Mendes ${ }^{4}$ \\ (D) https://orcid.org/0000-0003-2462-7847 \\ Pedro Bezerra ${ }^{1}, 2$ \\ (D) https://orcid.org/0000-0001-8219-5427 \\ Filipe Manuel Clemente 1,5 \\ (D) https://orcid.org/0000-0001-9813-2842
}

Abstract - The aims of this study were: (i) to describe weekly variations of acute load (AL), acute:chronic workload ratio, delayed onset muscle soreness (DOMS), and fatigue; (ii) to analyze variations of weekly workload and well-being in three periods of the season (P1, P2, and P3); and (iii) to analyze the relationships between workload and well-being measures. Fifteen professional basketball players from a first-league European club were monitored throughout the season using the CR-10 Borg scale and the Hooper questionnaire. Weekly $\mathrm{AL}$ and acute:chronic workload ratio (ACWR) were weekly calculated for monitoring of the internal load. In addition, DOMS and fatigue values were weekly calculated. Greater AL, DOMS, and fatigue values were found during the early season, and the highest ACWR value was found during the second period. Overall, AL presented large correlations with DOMS $(r=0.60)$ and fatigue $(r=0.62)$. The results of this study indicate that load is higher in the first period and then decreases throughout the season. The results also showed that AL is more closely related to well-being parameters than ACWR.

Key words: Athletes; Basketball; Training; Workload.

Resumo - O objetivo deste estudo foi: (1) descrever as variaçôes semanais de carga aguda (CA), razão da carga de trabalho aguda:crônica, dor musuclar tardia (DOT) e fadiga; (ii) analisar as variações da carga semanal de trabalho e bem-estar entre três periodos da temporada (P1, P2 e P3); e (iii) analisar as relaçôes entre carga de trabalho e medidas de bem-estar. Quinze jogadores profissionais de basquetebol de um clube de primeira liga Européia foram monitorados ao longo de uma temporada utilizando a escala CR-10 Borg e o questionário de Hooper. A CA semanal e a razão da carga de trabalho aguda:crônica (RCTAC) foram calculadas semanalmente para monitorar a carga interna. Além disso, os valores de DOT e fadiga foram calculados semanalmente. Maiores valores da CA, DOT e fadiga foram ensontrados durante o início da temporada e o maior valor de RCTAC foi encontrado durante o segundo periodo. No geral, a CA apresentou grandes correlaçóes com a DOT $(r=0,60)$ e fadiga $(r=0,62)$. Os resultados deste estudo indicam que a carga é maior no primeiro periodo e depois diminui ao longo da temporada. Os resultados também motraram que a CA está mais relacionada com os parâmetros de bem-estar do que a RCTAC.

Palavras-chave: Atletas; Basquetebol; Carga de trabalho; Treinamento.
1 Instituto Politécnico de Viana do Castelo. Escola Superior Desporto e Lazer. Viana do Castelo. Portugal.

2 The Research Centre in Sports Sciences. Health Sciences and Human Development. Vila Real. Portugal.

3 Federal University of Mato Grosso. Cuiabá, MT. Brazil.

4 University of Lisboa. Faculty of Human Kinetics. Lisboa. Portugal.

5 Instituto de Telecomunicações. Delegação da Covilhã. Lisboa. Portugal.

Received: July 22, 2020

Accepted: October 20, 2020

How to cite this article Ferreira F, Camões M, Lima RF, Silva R, Castro HO, Mendes B, Bezerra P, Clemente FM. Variations of workload and well-being measures across a professional basketball season. Rev Bras Cineantropom Desempenho Hum 2021, 23:e75863. DOl: http://doi. org/10.1590/1980-0037.2021v23e75863

Copyright: This work is licensed under a Creative Commons Attribution 4.0 International License. 


\section{INTRODUCTION}

Basketball is an intermittent team sport that involves high-intensity actions with brief interruptions ${ }^{1}$. Thus, athletes must be physically and psychologically well prepared for the specific needs of the sport. According to study conducted with male basketball players ${ }^{2}$, there are about 1000 total movement patterns, with change of movement occurring every 2-3 seconds on average (usually, these are changes of direction, accelerations, or rapid decelerations).

Individuality is an essential principle of training because different adaptations may occur between athletes presented with the same stimulus ${ }^{3}$. Quantifying the specific demands of a sport is important for developing team training regimens and analyzing individual athletic performances ${ }^{4}$. The monitoring of training loads is of utmost importance, as they assist coaches in understanding athletes' responses to stimuli, allowing training to be increasingly individualized and adjusted, thereby minimizing risks of overreaching, detraining, and injury ${ }^{5}$. However, determining the process that should be implemented to reach the desired workload is complex and requires precise analysis and objective and subjective measures, combined with the experience and perspective of coaches ${ }^{6}$.

Quantifying the training load is one of the possibilities for conducting such an analysis. This method can be divided into two main dimensions: (i) external load and (ii) internal load ${ }^{7}$. External load represents the physical demands derived from external stimulus applied to the athlete. It is monitored based on the athletes' work during training and/or matches according to various parameters, such as distance-based and accelerometrybased measures ${ }^{8}$. These types of external measures are usually obtained by global positioning systems (GPSs) and inertial sensor units (IMUs), which are usually integrated into GPSs ${ }^{9}$. On the other hand, internal load is the psychobiological response to the stimuli imposed by the external load. It can be measured by heart rate, rate of perceived exertion (RPE), and blood lactate concentration, among other factors that are fundamental to the athlete's perception of the load determination and adaptation ${ }^{10}$. Internal load can be objectively or subjectively quantified. Thus, numerous methods have been developed as monitoring tools to quantify internal training load. Among them, RPE scales are interesting instruments due to their validity and reliability, as well as their low cost and easy application in the majority of contexts ${ }^{11}$. RPE represents a measure of intensity. However, multiplication of the training session duration by RPE scores has been used to determine the load volume ${ }^{12}$.

In training load monitoring, weekly load determination is also crucial to understanding progressions and changes between weeks. In these terms, acute load (AL) represents the load accumulated in a regular training week, but when greater ALs are imposed on athletes, they experience more fatigue ${ }^{5}$. Chronic load is the average weekly load and is usually calculated over the most recent four weeks; higher progressive chronic load values are 
related to greater capacity to overcome $\mathrm{ALs}^{5-9}$. The relationships between acute and chronic loads (calculated by dividing AL by chronic load) are denoted as the acute:chronic workload ratio (ACWR). This measure can be useful in describing the exposure of athletes to injury risk scenarios (load spikes or severe load decreases ) and identifying weekly variations (to control progression or overload strategies) ${ }^{13,14}$.

Some studies ${ }^{15}$ have shown that it is especially important to monitor players' training load and well-being statuses, as this type of monitoring helps to maximize players' physical performance while avoiding poor overreaching or exposure to injury. Moreover, the understanding of the link between load and well-being must be improved. Well-being can be subjectively quantified using questionnaires (e.g., the Hopper questionnaire) and may represent an important way to track changes in variables such as delayed onset muscle soreness (DOMS) fatigue, stress, sleep quality, or mood ${ }^{16}$.

Mood states (e.g., tension, anger, depression) can be useful for adjusting workloads and assessing overtraining ${ }^{17}$. Anxiety and stress can impair or improve athletic performance and are present in competitive environments. Both training sessions and competitions present stress factors and influence the well-being of athletes. Due to the sport characteristics, basketball players have decreased hemoglobin levels and higher stress levels in the competitive phase ${ }^{18}$.

The aims of this study were: (i) to describe the weekly variations of AL, acute:chronic workload ratio, DOMS, and fatigue; (ii) to analyze weekly variations of AL, acute:chronic workload ratio, DOMS, and fatigue in three periods of the season (P1, P2, and P3); and (iii) to analyze the relationships between load and well-being measures.

\section{METHODS}

\section{Participants}

Fifteen professional basketball players from a first-league European club $(27.1 \pm 5.2$ years old; $195.3 \pm 9.9 \mathrm{~cm} ; 97.2 \pm 13.1 \mathrm{~kg} ; 7.6 \pm 5.6$ years of experience in elite basketball) participated in this study. Inclusion criteria were: (i) players participated in $80 \%$ of all training sessions of the season; and (ii) players did not stop practice training for more than two weeks. The experimental approach was presented to participants, after being informed, they signed the free consent form. The ethical standards of the Declaration of Helsinki for studies with humans were followed. The experiment was approved by the ESDL-IPVC scientific council .

\section{Experimental approach}

This study followed an observational analytic prospective cohort design. Analysis of variation tested differences of training load and well-being measures in 3 periods of the season (first period (P1) - week 1 to week 14; second period (P2) - week 15 to week 28; and last period (P3) - week 29 to week 42). Correlation analysis was performed to test relationships 
between load and well-being. The research had duration of eleven months, from August to June.

\section{Internal load}

The CR-10 Borg scale ${ }^{19}$ was used to monitor players' perceptual exertion by answering the question - always asked by the same researcher - "How difficult was the training session?”. This question was always asked $30 \mathrm{~min}$ utes after the training session/match and its classification varies between 1 (very light activity) and 10 (maximal exertion). Values collected were multiplied by the duration of the training/match (in minutes) resulting in s-RPE (session-RPE), which allows assessing the internal load ${ }^{7}$. Players were familiarized with the scale and answers were individually provided.

Using s-RPE, acute load and acute: chronic workload ratio (ACWR) were calculated. Acute load represents the sum of the internal load of each session during a week. ACWR represents the acute load divided by the average load of the past 28 days (4 weeks) ${ }^{20}$. Both acute load and ACWR were calculated in each week for each of player.

\section{Well-being}

The Hooper questionnaire ${ }^{16}$ was used to analyze well-being parameters. Athletes were familiar with the scale after a session dedicated to procedures.

The Hooper questionnaire was applied every morning, $30 \mathrm{~min}$ before the training session or game. Four categories were analyzed: (i) stress; (ii) fatigue; (iii) sleep; and (iv) delay onset muscle soreness (DOMS). The seven-point scale version was used, in which for DOMS, stress and fatigue 1 means very very low and 7 means very very high and regarding sleep, 1 means very very good, and 7 means very very poor ${ }^{5}$. Questionnaire answers were individually collected. The Hooper index was calculated based on the sum of 4 categories - rate corresponding to each item and the weekly value corresponding to each category was calculated based on the sum of all weekly rates.

\section{Statistical procedures}

Results were expressed as mean, SD and 90\% confidence intervals, unless otherwise stated. The Kolmogorov - Smirnov test was performed to assess sample normality and the Levene test was used to analyze homogeneity before performing further inferential tests. Associations between training load measures and well-being variables were made using the Pearson correlation test $(r)$. The magnitude of correlations was defined as follow ${ }^{21}$ $\mathrm{r}<0.1$, trivial; $0.1<\mathrm{r} \leq 0.3$, small; $0.3<\mathrm{r} \leq 0.5$, modern; $0.5<\mathrm{r} \leq 0.7$, large; $0.7<\mathrm{r} \leq 0.9$, very large; and $\mathrm{r} \geq 0.9$, nearly perfect. Correlations were always represented with $90 \%$ confidence intervals. Within-group changes across the 3 in-season periods were assessed using repeated-measures analysis of variance, followed by Tukey post hoc test to determine the $\mathrm{P}$ value in pairwise comparisons. Significance level was set at $\mathrm{P}<.05$. Standardized Cohen's effect sizes (d) were also calculated to determine the magnitude 
of pairwise comparisons. Hopkins' thresholds were used for the interpretation of inferences about the effect size magnitude ${ }^{22}$ : $\mathrm{d}<0.2$, trivial; 0.2 $<\mathrm{d} \leq 0.6$, small; $0.6<\mathrm{d} \leq 1.2$, moderate; $1.2<\mathrm{d} \leq 2.0$, large; and $\mathrm{d} \geq 2.0$, very large. The SPSS software (version 24.0; IBM, Armonk, NY) was used for the analysis.

\section{RESULTS}

Weekly load and acute:chronic workload ratio (ACWR) variations during the season are shown in Figure 1. The week with the highest weekly load is w2 and, on the other hand, the week with the lowest weekly load is w18. The week with the highest ACWR value is w14 and w18 presents the lowest ACWR value of the season.

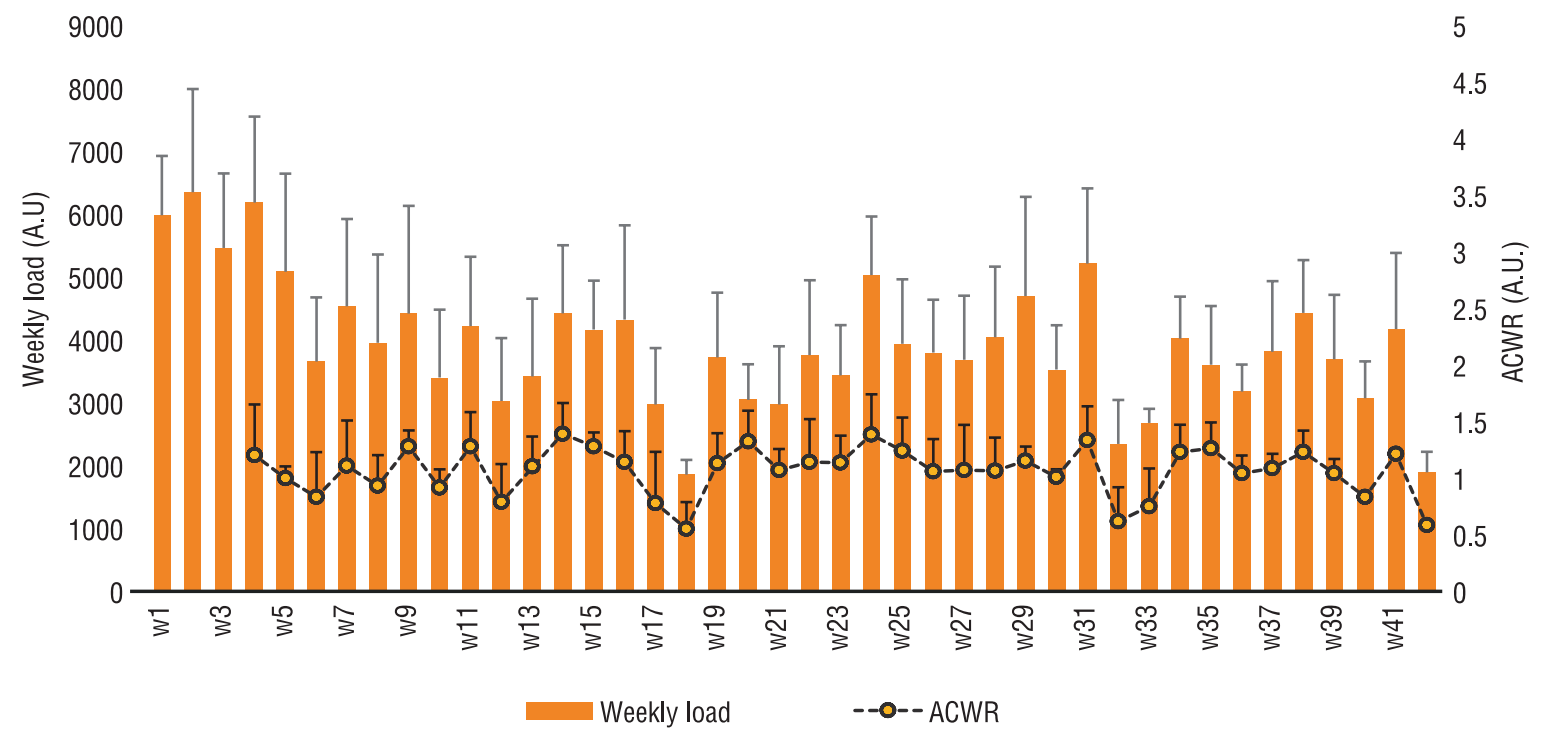

Figure 1. Weekly load and acute:chronic workload ratio (ACWR) variations throughout the season.

Figure 2 shows the DOMS and fatigue values, also showing w18 as the week with the lowest recorded values, like values found in the first figure. DOMS and fatigue values are higher in w7.

In this study, 42-week data were collected and analyzed, later divided into 3 periods of the season (early, mid and end). Comparison of training loads and well-being in these periods are shown in Table 1. Regarding the first table, the highest AL (Acute Load), DOMS and Fatigue values were found in the first period of the season (P1). In the mid period (P2), the highest ACWR and lowest DOMS values were recorded. The last period (P3) of the season, the lowest AL, ACWR, and Fatigue values were recorded.

Statistically significant differences $(p)$ in relation to AL in $\mathrm{P} 1$ vs $\mathrm{P} 2(p=$ $0,032)$ and $\mathrm{P} 1$ vs $\mathrm{P} 3(p=0,024)$ were observed. No significant differences were found in the remaining variables and periods.

Regarding ACWR, all three periods of the season showed trivial relationships between them $(\mathrm{P} 1$ vs $\mathrm{P} 2$ : $\mathrm{d}=0.135 ; \mathrm{P} 1$ vs $\mathrm{P}$ : $\mathrm{d}=0.046$; $\mathrm{P} 2$ 
vs P3: $\mathrm{d}=0.178)$. Regarding DOMS, small relationship in the P1 vs P2 period $(\mathrm{d}=0.258)$ and trivial relationship in the remaining two periods $(\mathrm{P} 1$ vs P3: $d=0.127$; P2 vs P3: 0.132) were observed. Regarding Fatigue, small relationship was observed when comparing early with mid and end periods (P1 vs P2: $d=0.401 ; P 1$ vs $P 3: d=0.568)$ and trivial when comparing the

30

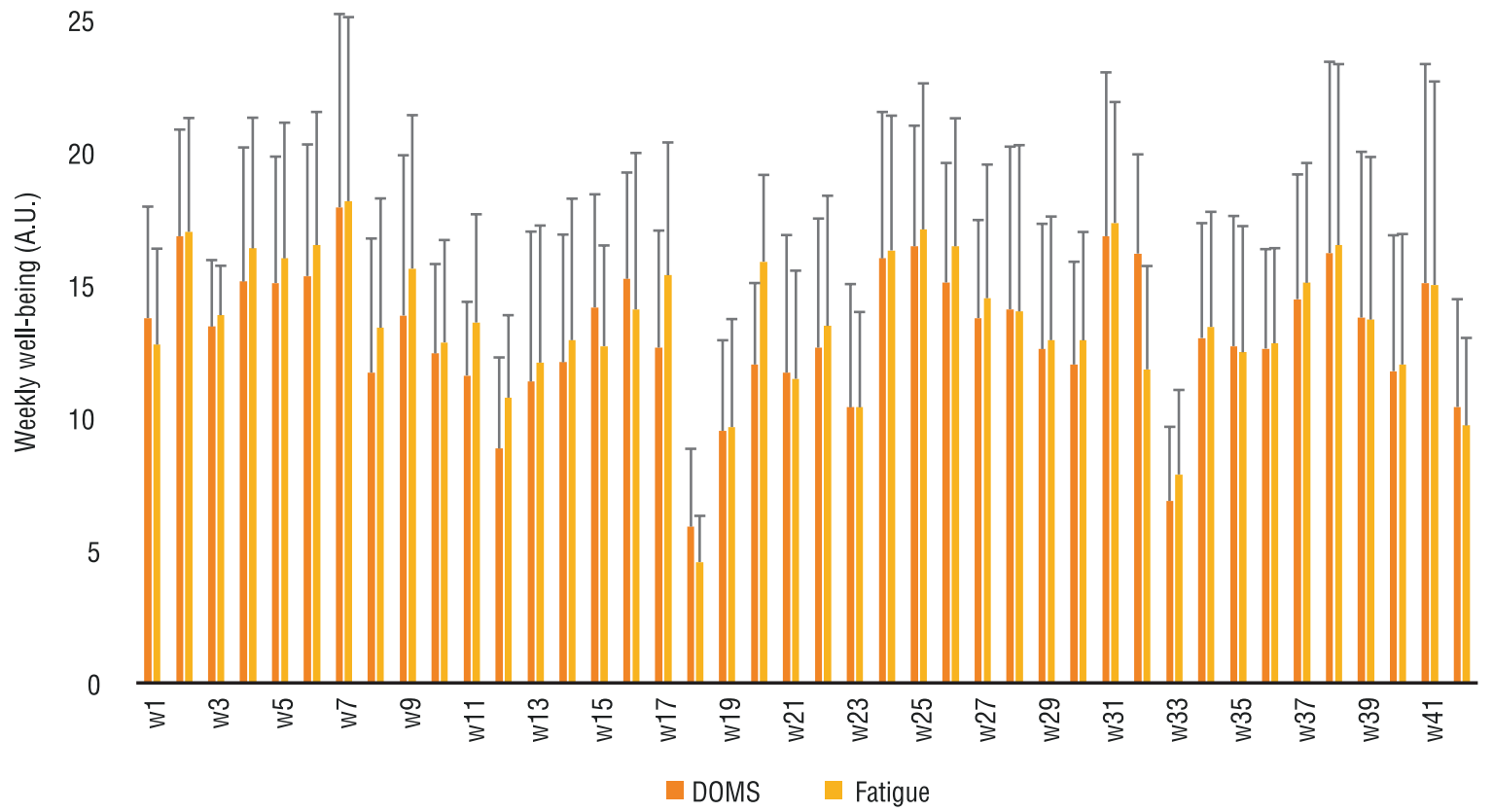

Figure 2. Delayed onset muscle soreness (DOMS) and fatigue variations throughout the season.

Table 1. Differences between periods of season (P1, P2, P3), considering training load and well-being.

\begin{tabular}{|c|c|c|c|c|c|}
\hline & $\begin{array}{c}\mathrm{P} 1 \\
(\text { mean } \pm \text { SD) }\end{array}$ & $\begin{array}{c}\mathrm{P} 2 \\
(\text { mean } \pm S D)\end{array}$ & $\begin{array}{c}\mathrm{P} 3 \\
(\text { mean } \pm \text { SD })\end{array}$ & $p$ & d | magnitude \\
\hline AL (A.U.) & $4578.99 \pm 1083.87$ & $3623.89 \pm 756.45$ & $3594.91 \pm 913.46$ & $\begin{array}{l}\text { P1 vs. P2: } 0.032 \\
\text { P1 vs. P3: } 0.024 \\
\text { P2 vs. P3: } 0.921\end{array}$ & $\begin{array}{l}\text { P1 vs. P2: } 1.022 \text { | Moderate } \\
\text { P1 vs. P3: } 0.982 \text { | Moderate } \\
\text { P2 vs. P3: } 0.035 \text { | Moderate }\end{array}$ \\
\hline ACWR (A.U.) & $1.07 \pm 0.21$ & $1.10 \pm 0.23$ & $1.06 \pm 0.22$ & $\begin{array}{l}\text { P1 vs. P2: } 0.720 \\
\text { P1 vs. P3: } 0.927 \\
\text { P2 vs. P3: } 0.247\end{array}$ & $\begin{array}{l}\text { P1 vs. P2: } 0.135 \text { | Trivial } \\
\text { P1 vs. P3: } 0.046 \text { | Trivial } \\
\text { P2 vs. P3: } 0.178 \text { | Trivial }\end{array}$ \\
\hline DOMS (A.U.) & $13.51 \pm 2.41$ & $12.83 \pm 2.85$ & $13.19 \pm 2.61$ & $\begin{array}{l}\text { P1 vs. P2: } 0.577 \\
\text { P1 vs. P3: } 0.747 \\
\text { P2 vs. P3: } 0.735\end{array}$ & $\begin{array}{l}\text { P1 vs. P2: } 0.258 \text { | Small } \\
\text { P1 vs. P3: } 0.127 \text { | Trivial } \\
\text { P2 vs. P3: } 0.132 \text { | Trivial }\end{array}$ \\
\hline Fatigue (A.U.) & $14.43 \pm 2.17$ & $13.29 \pm 3.38$ & $13.11 \pm 2.47$ & $\begin{array}{l}\text { P1 vs. P2: } 0.399 \\
\text { P1 vs. P3: } 0.191 \\
\text { P2 vs. P3: } 0.835\end{array}$ & $\begin{array}{l}\text { P1 vs. P2: } 0.401 \text { | Small } \\
\text { P1 vs. P3: } 0.568 \text { | Small } \\
\text { P2 vs. P3: } 0.061 \text { | Trivial }\end{array}$ \\
\hline
\end{tabular}

Note. P1: week 1 to week 14; P2: week 15 to week 28; P3: week 29 to week 42; Acute load: sum of all RPE of the week; ACWR: acute:chronic workload ratio; A.U.: arbitrary units; DOMS: delayed onset muscle soreness

Table 2. Correlation coefficient (mean $[95 \% \mathrm{Cl}]$ ) between well-being and load measures.

\begin{tabular}{lcc}
\hline & Acute load (A.U.) & ACWR (A.U.) \\
\hline DOMS (A.U.) & $0.60[0.36 ; 0.78]$ & $0.45[0.17 ; 0.66]$ \\
& Large & Moderate \\
Fatigue (A.U.) & $0.62[0.39 ; 0.78]$ & $0.55[0.30 ; 0.73]$ \\
& Large & Large \\
\hline
\end{tabular}

Note. DOMS: delayed onset muscle soreness; ACWR: acute:chronic workload ratio; A.U.: arbitrary units 
last two periods of the season (P2 vs P3: $\mathrm{d}=0.061)$.

Large correlation was found between DOMS and Acute Load (0.60), Acute Load and Fatigue (0.62) and between Fatigue and ACWR (0.55). Regarding correlation between ACWR and DOMS, moderate relationship was found (0.45).

\section{DISCUSSION}

This study aimed to analyze AL, acute:chronic workload ratio, DOMS, and fatigue variations throughout a basketball season, as well as the relationships between load and well-being measures. The main finding was that AL, DOMS, and fatigue values were greater at the beginning of the season than during in-season periods, although only AL presented significant differences between periods. In addition, greater DOMS and fatigue values were related to greater $A L$ and $A C W R$ values.

The highest values of variables were found during P1 as follows: Weekly Load (week 2), ACWR (week 14), DOMS (week 7), and Fatigue (week 7). On the other hand, the lowest values were found during P2. These values may be higher in the first period due to the high training volume characteristic of the pre-season period ${ }^{23}$. Recent research regarding weekly workloads of elite basketball players showed pattern of higher AL in the first weeks of the season, which is consistent with our results ${ }^{24}$. Also, the lowest values found during in-season periods (P2 and P3) corroborate the study of Manzi et al. ${ }^{25}$, which revealed that AL was higher during weeks without matches than weeks with one or more matches. This may be because this is usually the period with the greatest number of matches, and, therefore, there is a decrease in the training load and more recovery sessions $s^{6,24}$.

Further, as AL increased or decreased throughout the season in the present study, similar and simultaneous pattern was observed for DOMS and fatigue. Conversely to the trend of decreasing AL until the end of the season, DOMS and fatigue remained consistently high throughout the season. This seems to be somewhat obvious, as high AL values during the first weeks of the season, as well as accumulated AL values during P2 and P3, are expected to cause fatigue in athletes ${ }^{26}$. Nevertheless, ACWR values were maintained within the "sweet spot" (between 0.8 and 1.3 A.U.), which means that a balance between acute and chronic loads was maintained throughout the season, diminishing the risks of injuries ${ }^{27}$. This can provide new insights into AL management and its consequences in relation to the fatigue/freshness of a team during a season, as well as the adjustment of training protocols in accordance with recovery strategies.

Analysis of variance found significant differences for AL only for two of the three periods observed: P1 vs. P2 ( $\mathrm{p}=0.032)$ and P1 vs. P3 ( $\mathrm{p}=0.024)$. These differences were also observed in a similar study conducted with volleyball players, although in that study, differences with respect to weekly ACWR values were also observed, which is in contrast with our findings ${ }^{5}$. However, in the study of Clemente et al. ${ }^{5}$, no significant differ- 
ences between DOMS and fatigue were found, which is consistent with results of the present study. As previously mentioned, higher AL values are expected during the first weeks of the season, following a leveling-off phase without major variations for the rest of the season ${ }^{25}$.

Considering the relationships between well-being measures and workload measures during a full season, large correlations were found between $\mathrm{AL}$ and well-being measures (DOMS and fatigue). Similar significant relationships between well-being and AL measures have been found in other studies on team sports ${ }^{5,28}$. On the other hand, ACWR showed large correlations with fatigue, but only moderate correlations with DOMS. In fact, a study conducted with 15 elite first-league European basketball players revealed that players presented greater fatigue levels during competition weeks in relation to regular weeks, although perceived AL was lower ${ }^{26}$. This is consistent with results of the present study, as significant decreases in $\mathrm{AL}$ were observed from the pre-season to the in-season period until the end of the season, while DOMS and fatigue levels remained high. It is imperative to monitor the lack of variation on well-being status during the in-season period, as it may cause significant decreases in team performance. This can be controlled by including tapering and recovery strategies during the training process, which may lead to decreases in fatigue and DOMS levels ${ }^{25}$.

The present study had some limitations. One of them was the sample size, as only one team was analyzed. Future studies should include more than one team with the aim of achieving greater consistency of findings. Also, possible dependencies on player position and external loads were not considered. It would be interesting to analyze AL, ACWR, training monotony variations, and strain based on internal and external measures throughout the season.

Despite these limitations, our study presents some practical applications. The most valuable evidence presented in this work is that greater AL values are expected during the first weeks of the season, whichdecrease before becoming stable during in-season phases. Although AL decreases throughout the season, fatigue and DOMS levels remain consistently high during the season. Even though well-being measures were largely correlated with workload measures, ACWR values were maintained in the safe zone throughout the three periods.

\section{CONCLUSION}

The aim of the present study was to analyze AL, ACWR, DOMS and fatigue variations throughout a basketball season, as well as the relationships between load and well-being measures. The results revealed that $\mathrm{AL}$ was significantly higher during the first period of the season when compared to the last two periods. However, AL was the only study variable that presented significant differences between pre-season and in-season periods. In addition, AL showed the strongest correlation with well-being parameters. On the other hand, ACWR values were consistent throughout 
the season. Thus, these results may provide coaches new insights about AL, ACWR, fatigue and DOMS variations throughout a season and enable them to adjust the training process accordingly.

\section{Acknowledgements}

This study was done as part of master thesis in sports training, Escola Superior de Desporto e Lazer, Instituto Politécnico de Viana do Castelo, Portugal.

\section{COMPLIANCE WITH ETHICAL STANDARDS}

\section{Funding}

This research did not receive any specific grant from funding agencies in the public, commercial, or not-for-profit sectors.

\section{Ethical approval}

Ethical approval was obtained from the local institute's research ethics committee - Scientific Council of ESDL-Polytechnic of Viana do Castelo and protocol was written following standards established by the Declaration of Helsinki.

\section{Conflict of interest statement}

The authors have no conflict of interest to declare.

\section{Author Contributions}

Conception and design of the experiment: MF, MC, RFL, RS, FMC. Performance of experiments: MF, MC, RFL, RS, HOC, BM, PB, FMC. Data analysis: MF, RFL, FMC. Contribution with reagents/research materials/analysis tools: MF, MC, RFL, RS, HOC, BM, PB, FMC. Article writing: MF, MC, RFL, RS, HOC, BM, PB, FMC. All authors read and approved the final version of the manuscript.

\section{REFERENCES}

1. Nunes JA, Costa EC, Viveiros L, Moreira A, Aoki MS. Monitoramento da carga interna no basquetebol. Rev Bras Cineantropom Desempenho Hum 2011;13(1):67-72.

2. Klusemann MJ, Pyne DB, Hopkins WG, Drinkwater EJ. Activity profiles and demands of seasonal and tournament basketball competition. Int J Sports Physiol Perform 2013;8(6):623-629.

3. Borresen J, Lambert MI. The Quantification of Training Load, Effect on Performance. Sport Med 2009;39(9):779-795.

4. Taylor JB, Wright AA, Dischiavi SL, Townsend MA, Marmon AR. Activity Demands During Multi-Directional Team Sports: A Systematic Review. Sport Med 2017;12;47(12):2533-2551.

5. Clemente FM, Silva AF, Clark CCT, Conte D, Ribeiro J, Mendes B, et al. Analyzing the Seasonal Changes and Relationships in Training Load and Wellness in Elite Volleyball Players. Int J Sports Physiol Perform 2020;15(5):731-740.

6. Rabelo FN, Pasquarelli BN, Gonçalves B, Matzenbacher F, Campo F, Sampaio $\mathrm{J}$, et al. Monitoring the intended and perceived training load of a professional futsal team over 45 weels: a case study. J Strength Cond Res 2016;30(1):134-140.

7. Foster $\mathrm{C}$. Monitoring training in athletes with reference to overtraining syndrome. Med Sci Sports Exerc 1998;30(7):1164-1168. 
8. Halson SL. Monitoring Training Load to Understand Fatigue in Athletes. Sport Med 2014;44(Suppl 2):139-147.

9. Malone JJ, Lovell R, Varley MC, Coutts AJ. Unpacking the Black Box : Applications and Considerations for Using GPS Devices in Sport. Int J Sports Physiol Perform 2017;12(Suppl 2):S218-S226.

10. Oliveira e Silva PMM, Mendes R, Santos P, Rocha JM. Fatores de carga externa e interna associados com a percepção subjetiva de esforço no futebol de elite. Cent Pesqui Desenvolv Desportivo 2016;1-14.

11. Haddad M, Chaouachi A, Wong DP, Castagna C, Hambli M, Hue O, et al. Influence of fatigue, stress, muscle soreness and sleep on perceived exertion during submaximal effort. Physiol Behav 2013;119:185-189.

12. Foster C, Florhaug JA, Franklin J, Gottschall L, Hrovatin LA, Parker S, et al. A New Approach to Monitoring Exercise Training. J Strength Cond Res 2001;15(1):109-115.

13. Bowen L, Gross AS, Gimpel M, Li F-X, Malone JJ, Lovell R, et al. Accumulated workloads and the acute:chronic workload ratio relate to injury risk in elite youth football players. Br J Sports Med 2017;51(5):452-459.

14. Maupin D, Schram B, Canetti E, Orr R. The Relationship Between Acute: Chronic Workload Ratios and Injury Risk in Sports: A Systematic Review. Open Access J Sport Med 2020;11:51-75.

15. Conte D, Kolb N, Scanlan AT, Santolamazza F. Monitoring Training Load and Well-Being During the In-Season Phase in National Collegiate Athletic Association Division I Men's Basketball. Int J Sport Physiol Perform 2018;13(8):1067-1074.

16. Hooper SL, Mackinnon LT. Monitoring Overtraining in Athletes. Recommendations. Sports Med 1995;20(5):321-327.

17. Chang C, Putukian M, Aerni G, Diamond A, Hong G, Ingram Y, et al. Mental health issues and psychological factors in athletes: Detection, management, effect on performance and prevention: American Medical Society for Sports Medicine Position Statement-Executive Summary. Br J Sports Med 2020;54(4):216-220.

18. Moreira A, Arsati F, Cury PR, Franciscon C, Simões AC, Oliveira PR, et al. The impact of a 17-day training period for an international championship on mucosal immune parameters in top-level basketball players and staff members. Eur J Oral Sci 2008;116(5):431-437.

19. Borg G. Perceived exertion and pain scales. Champaign IL, USA: Human Kinetics; 1998.

20. Hulin BT, Gabbett TJ, Lawson DW, Caputi P, Sampson JA. The acute:chronic workload ratio predicts injury: high chronic workload may decrease injury risk in elite rugby league players. Br J Sports Med 2016;50(4):231-236.

21. Hopkins WG, Marshall SW, Batterham AM, Hanin J. Progressive statistics for studies in sports medicine and exercise science. Med Sci Sports Exerc 2009;41(1):3-13.

22. Batterham AM, Hopkins WG. Making Meaningful Inferences about Magnitudes. Int J Sports Physiol Perform 2006;1(1):50-7.

23. Meckel Y, Doron O, Eliakim E, Eliakim A. Seasonal Variations in Physical Fitness and Performance Indices of Elite Soccer Players. Sports (Basel) 2018;6(1):14.

24. Salazar H, Svilar L, Aldalur-Soto A, Castellano J. Differences in weekly load distribution over two euroleague seasons with a different head coach. Int J Environ Res Public Health 2020;17(8):2812.

25. Manzi Vi, D’Ottavio S, Impellizzeri FM, Chaouachi A, Chamari K, Castagna C. Profile of Weekly Training Load in Elite Male Professional Basketball Players. J Strength Cond Res 2010;24(5):1399-1406.

26. Clemente FM, Mendes B, Bredt ST, Praça GM, Silvério A, Carriço S, et al. Perceived Training Load, Muscle Soreness, Stress, Fatigue, and Sleep Quality in Professional Basketball. J Hum Kinet 2019;67:199-207.

27. Gabbett TJ. The training-injury prevention paradox: should athletes be training smarter and harder? Br J Sports Med 2016;50(5):273-280.

28. Clemente FM, Mendes B, Palao JM, Silvério A, Carriço S, Calvete F, et al. Seasonal player wellness and its longitudinal association with internal training load: study in elite volleyball. J Sports Med Phys Fitness 2019;59(3):345-351. 